\title{
Molecular biology of trophoblast interferons and studies of their effects in vivo
}

\author{
A. P. F. Flint†, T. J. Parkinson*, H. J. Stewartł, J. L. Vallet* and \\ G. E. Lamming* \\ AFRC Research Group on Hormones and Farm Animal Reproduction. *University of Nottingham, \\ Faculty of Agricultural Science, Sutton Bonington, Loughborough, Leics LE12 5RD, UK; \\ †Institute of Zoology, Regent's Park, London NWI $4 R Y, U K$; and \\ $\ddagger$ IAPGR Babraham, Cambridge CB2 4AT, UK
}

\begin{abstract}
Summary. Southern blotting of bovine genomic DNA indicated the presence of at least 3 bovine tIFN genes. The full DNA sequence of one of these genes, thought to be expressed in trophoblast, has been determined, including 193 bp of 5 non-coding region. The inferred amino acid sequence of bovine tIFN is more similar to ovine tIFN $(80 \%)$ than to bovine IFN- $\alpha_{n}(70 \%)$. The $5^{\prime}$ flanking sequence has some similarity with bovine IFN- $\alpha_{\text {II }}$, and may contain a viral response element.

A recombinant bovine $\alpha_{\mathrm{I}}$ interferon (Ciba Geigy; brIFN), resembling tIFN, extended oestrous cycle length in sheep when administered by intrauterine infusion over the period, Days 12-15 after oestrus, when maternal recognition of pregnancy occurs. Intramuscular injection was only effective at the doses used if given over a longer period (i.e. Days 9-15).

Our experiments indicate that both IIFN and brIFN inhibit luteolysis by preventing a rise in endometrial oxytocin receptor concentrations, and suggest that tIFN achieves this by extending the time for which progesterone suppresses oxytocin receptor development. Further studies are required to confirm this hypothesis and to elucidate the interaction of the effects of progesterone and tIFN in endometrial cells.
\end{abstract}

Keywords: trophoblast interferons; pregnancy recognition; luteolysis; embryo

\section{Introduction}

Major advances in our understanding of the factors controlling the corpus luteum during the oestrous cycle and in early pregnancy in polyoestrous domestic ruminants arose from the studies of Wiltbank \& Casida (1956), Denamur \& Mauleon (1963), Moor \& Rowson (1964), Caldwell et al. (1969), Goding et al. (1972) and others between 1955 and 1970. Experimental surgical procedures, including hysterectomy, hemi-hysterectomy and utero-ovarian autotransplantation, led to the identification of the uterus as a source of luteolytic compounds at the end of the oestrous cycle in sheep. Subsequently, the discovery that prostaglandin (PG) F-2 $\alpha$ is a venoconstrictor in dogs and is luteolytic in rats led to its identification as a possible luteolysin of uterine origin in ruminants (for references see Flint \& Hillier, 1975). Later studies showed that PGF-2 $\alpha$ was released in episodes at luteolysis in the sheep, cow and goat (see Flint et al., 1990).

The observation that corpus luteum function is maintained in early pregnancy led to the realization that the uterine luteolytic mechanism must be inhibited or overcome in some way between Days 12 and 18 of pregnancy in sheep and Days 17 and 22 in the cow and Short (1969) coined the phrase 'the maternal recognition of pregnancy' to draw attention to the mechanisms involved. Experiments in which embryos were flushed from the ovine uterus in early gestation, or transferred into the uterus in non-pregnant animals showed that the last time at which the blastocyst could be 
removed without prolonging luteal function was Day 12, and Day 12 was also the latest time at which embryos transferred into the uterus would maintain corpus luteum function. Day 12 is therefore known as the time of the maternal recognition of pregnancy in the sheep.

In 1967, Rowson \& Moor showed in the sheep that the effect of transferring an embryo to the uterus could be mimicked by the infusion of aqueous extracts of blastocysts. This experiment identified the blastocyst itself as one possible source of an antiluteolytic substance responsible for the maternal recognition of pregnancy, and subsequent attempts to identify this substance led to its partial purification and identification as a protein, named trophoblastin (Martal et al., 1979). This protein was later found to be identical to the major secretory product of the blastocyst in vitro, identified after culture in the presence of labelled amino acids and subsequent two-dimensional polyacrylamide gel electrophoresis, which Godkin et al, (1984) named ovine trophoblast protein 1. This protein was produced by trophoblastic vesicles in culture, bound to endometrial receptors, and prolonged the luteal phase of the cycle when administered to the uterus in purified form (see Bazer et al., 1986).

The final identification of the ovine antiluteolysin was achieved simultaneously in $1987 / 8$ by groups in Europe and the USA, using amino acid sequencing of the purified protein and cDNA cloning (Stewart et al., 1987; Imakawa et al., 1987; Charpigny et al., 1988; Charlier et al., 1989). These groups showed that the purified protein was a member of the interferon (IFN)- $\alpha_{11}$ family of proteins, with a greater than $70 \%$ homology to known bovine IFN- $\alpha_{11}$ sequences. More recently the trophoblast IFNs (tIFNs) have been shown to possess antiviral activity (Pontzer et al., 1988; Roberts et al,, 1989), and to bind to endometrial receptors (Stewart et al., 1987; Hansen et al., 1989). Furthermore, detailed studies have been carried out by in-situ hybridization on the time of onset and cessation of secretion of tIFNs (Farin et al., 1989) and several studies have been made of the effects of pure IFNs administered systemically and into the uterus (Plante et al., 1988; Stewart et al., 1989a). Bovine tIFNs have also been cloned and sequenced (Imakawa et al., 1989).

These studies have highlighted a number of questions (see Stewart, 1990) which are the subject of current research. These include the mechanisms controlling tIFN secretion, the mechanism of action of tIFNs, in particular their effects on oxytocin receptor concentrations in the endometrium, and possible compounds acting synergistically with trophoblastic interferons. The work described here was undertaken to attempt to clarify these questions.

\section{The molecular biology of trophoblast interferon synthesis: studies on the number of interferon- $\alpha$ genes expressed in the trophoblast}

Several cDNAs encoding sheep and cow tIFNs have been cloned and sequenced (Imakawa $e t$ al,, 1987, 1989; Charlier et al., 1989; Stewart et al., 1989b, 1990) and amino acid sequences have also been determined for sheep tIFNs separated by HPLC ( $J$. Martal, personal communication). The results show that, in the sheep, there are at least 5 isoforms of the protein and in the cow at least 4 , having minor differences in nucleotide and in amino acid sequences. None of the bovine trophoblast cDNAs is identical to any of the 6 bovine IFN- $\alpha$ genes previously sequenced. It is not known whether the different isoforms represent different alleles of the protein, or result from the expression of more than one gene. We have approached this question by Southern blotting of bovine genomic DNA, using a cDNA isolated from a bovine blastocyst cDNA library (Stewart et al., 1990).

A bovine cDNA library was prepared from mRNA obtained from a bovine conceptus on Day 18; cDNA was cloned in $\lambda \mathrm{gt} 10$ and positive clones were isolated by probing with labelled bovine tIFN cDNA. The sequence of one cDNA isolated from this library was identical to the nucleotide sequence of a bovine gene subsequently isolated using the bovine cDNA to probe a bovine genomic library (see below).

For Southern blotting, bovine DNA isolated from blood cells was treated with proteinase K, extracted with phenol and precipitated with ethanol; this DNA was restricted with Bam $\mathrm{H} 1$, Hind III and Eco Rl and subjected to electrophoresis on an $0.8 \%$ agarose gel before blotting onto nylon. 
This blot was probed with radiolabelled bovine tIFN cDNA obtained as described above, and at least 3 genes were identified in the Bam HI and Hind III digests (Fig. 1). Restriction with Eco RI generated more than 3 hybridizing bands; this presumably reflects the presence of an Eco R1 site in the region to which the probe hybridizes, in the gene described (and possibly in other genes). One of the Hind III fragments was $4 \mathrm{~kb}$ in length, and this may correspond to the fragment subsequently cloned (see below).
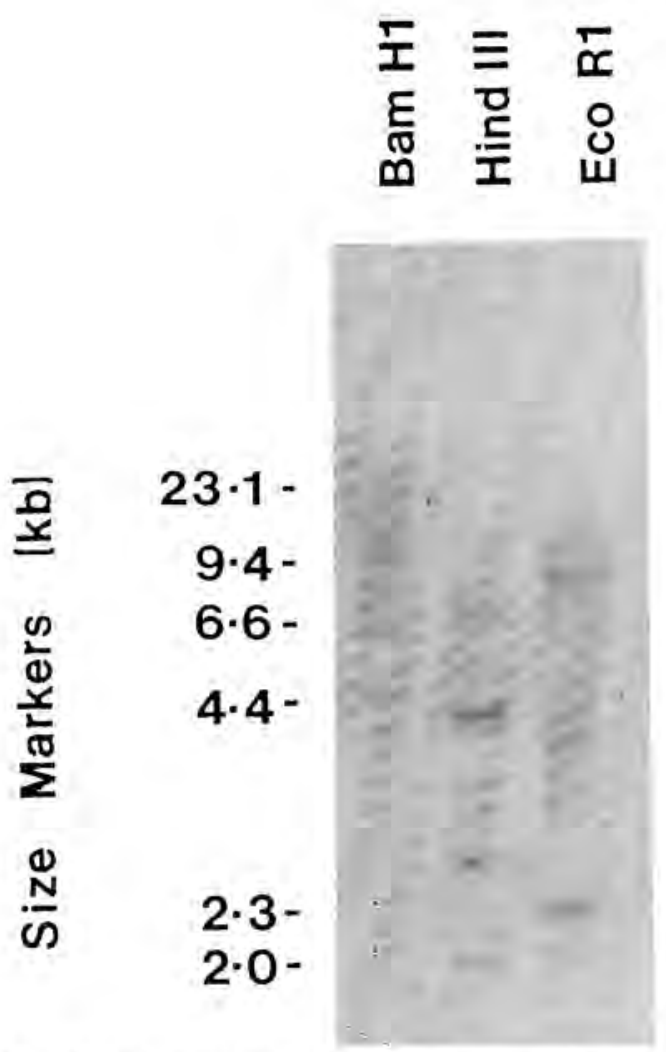

Fig. 1. Southern analysis of bovine genomic DNA $(20 \mu \mathrm{g})$ restricted with Bam H1, Hind III and Eco R1, hybridized to bovine tIFN cDNA. Size markers comprising Hind III-restricted wild-type $\lambda$ DNA are indicated.

\section{Genomic sequencing and identification of upstream viral response sequences}

Twenty positive clones identified in a bovine genomic library, prepared as a Sau $3 \mathrm{~A}$ partial digest of bovine DNA cloned into the Bam H1 site of $\lambda 2001$ (kindly donated by J. Walker and S. Heathy, MRC Laboratory of Molecular Biology, Hills Road, Cambridge, UK) were identified by probing with a radiolabelled ovine tIFN cDNA. After a second screening using a 54-mer oligonucleotide probe for the ovine tIFN, a $3.8 \mathrm{~kb}$ Hind III fragment, derived from a $20 \mathrm{~kb}$ positive genomic clone, was subcloned into Bluescribe. Single-stranded DNA sequencing was performed on overlapping subclones in both directions. The resulting genomic sequence (Fig. 2; Stewart et al., 1990) included 193 base pairs upstream of the translation initiation codon, 585 base pairs of the coding region, and at least 300 base pairs at the $3^{\prime}$ end of the gene. In common with other IFN genes this sequence contains no introns. 
$-120$

TGACTACATT TCCTAGGTCA AACAGAAAAT ATCTAACTGA AAACACAAAC AGGAAGTGAG $-60$

AGAGAAATTT TCGGATAATG AGTACCGTCT TCCCTATTTA AAAGCCTTGC TTAGAACGAT 1 CATCATCAGA GAACCTACCT GAAGGTTCAC CCAGACCCCA TCTCAGCCAG CCCAGCAGCA 60

GCCACATCTT CCCC ATGGC CTTCGTGCTC TCTCTACTGA TGGCCCTGGT GCTGGTCAGC \begin{tabular}{lllllllllllllll}
\hline$M$ & $A$ & $F$ & $V$ & $L$ & $S$ & $L$ & $L$ & $M$ & $A$ & $L$ & $V$ & $I$ & $V$ & $S$
\end{tabular} S1

121

TACGGCCCGG GACGATCTCI GGGTTGTTAC CIGTCIGAGG ACCACATGCT AGGTGCCAGG

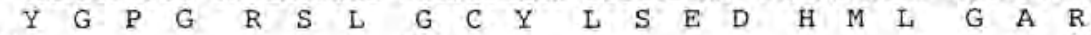

S16 $\$ 231$

GAGAACCTCA GGCTCCTGGC CCGATGGAC AGACTCTCTC CTCATCCCTG TCTGCAGGAC

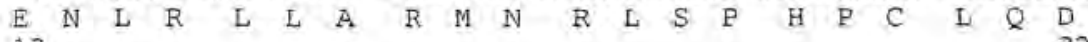
13

241

AGAAAAGACT ITGGTCTTCC TCAGGAGATG GTGGAGGGCA ACCAGCTCCA GAAGGATCAG $\begin{array}{llllllllllllllllllll}R & K & D & F & G & L & P & Q & E & M & V & E & G & N & Q & L & Q & K & D & Q \\ 33 & & & & & & & \end{array}$

301

GCTATCTCTG TGCTCCATGA GATGCTCCAG CAGTGCTTCA ACCTCTICTA CACAGAGCAC A. I S V L H E $M$ L L $Q$ Q 53

361

TCGTCTGCTG CCTGGAACAC CACCCICCTG GAGCAGCTCT GCACTGGGCT CCAACAGCAG

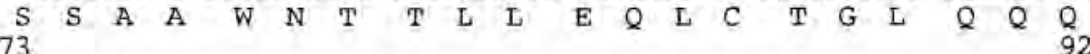

421

CTGGAGGACC TGGACGCCTG CCTGGGCCCA GTGATGGGAG AGAAAGACTC TGACATGGGA

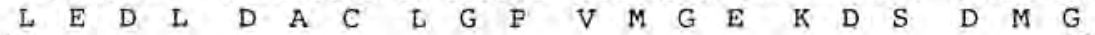
93

481

AGGATGGGCC CCATTCTGAC TGTGAAGAAG TACTTCCAGG GCATCCATGT CTACCTGAAA

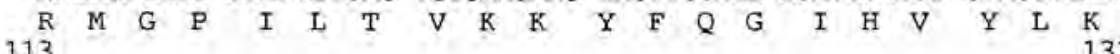

541

GAAAAAGAAT ACAGTGACTG CGCCTGGGAA ATCATCAGAA TGGAGATGAT GAGAGCCCTC

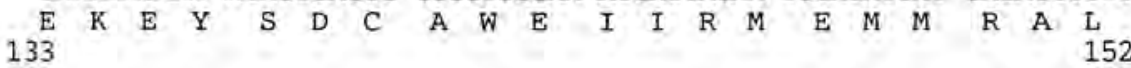

601

TCTTCATCAA CCACCTIGCA AAAAAGGTTA AGAAAGATGG GTGGAGATCT GAACTCACTT

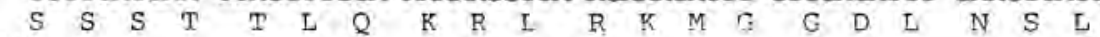
153

661.

TGAGATGACT CTCGCIGACT AAGATGCCAC ATCACCTTCG TACACTCACC TGTGTTCATT $72 \overline{1}$ TCAGAAGACT CIGATTTCIG CITCAGCCAC CGAATTCATT GAATTACTTT AACTGATACT 781 841

TIGTCAGCAG CAATAAGCAA GTAGATATAA AAGTACTCAG CTGTAGGGGC ATAAGTCCTT AAGTGATGCC TGCCCTGATG TTATCIGTIG TIGATTTATG TATTCCTICT TGCATCTAAC 901 961

ATACTPAAAA TGTTAGAAAT TTGTAAAGT ACATTTCATT TGLACATCTA TIAAAATTTC

TAAAACATGT TTACCATTTT GTGTTATTAA AITTGTCCTT TGTTCTATTT ATTAAATCAA

Fig. 2. Sequence of the bovine tIFN gene, including $5^{\prime}$ and $3^{\prime}$ flanking sequences. The deduced amino acid sequence shows the signal peptide (S1-S23), and the 172-residue IFN gene product. Putative CAAT (bases -105 to -99) and TATA (bases -26 to - 18) boxes are underlined, as are the translation start and termination codons and polyadenylation signal Vertical arrows mark the transcription start sites. (From Stewart et al.n 1990.) 
There are three pieces of evidence which make it appear likely that this genomic sequence codes for a protein expressed in the blastocyst. Firstly, the nucleotide sequence is identical with that of a cDNA isolated from a bovine cDNA library (see above); secondly, this sequence has a closer homology with that of ovine IIFN than with any other bovine IFN, and a lack of identity with any previously described bovine IFN- $\alpha$; and lastly the gene was isolated using a probe coding for an ovine tIFN; this probe hybridizes to an mRNA from bovine trophoblast with expected size and time course of appearance during pregnancy.

The cDNA was 727 base pairs long and included the whole coding region of the protein. The amino acid sequence for which this cDNA and the gene code, and their nucleotide sequences, differed from all 3 bovine cDNA sequences described by Imakawa et al (1989). There are 8 nucleotide and 3 amino acid differences compared with the coding sequence reported by Imakawa et al. (1989). The existence of 4 variants of bovine tIFN cDNA sequence is consistent with the identification of several isoforms of the protein by two-dimensional polyacrylamide gel electrophoresis (see Bazer et al., 1986).

The predicted amino acid sequence of bovine tIFN had a higher homology with ovine tIFN than with the bovine IFN- $\alpha_{11}$ sequence described previously (Table 1). The amino acid sequence of bovine tIFN was $70 \cdot 4 \%$ identical to bovine IFN- $\alpha_{11}$.

Table 1. Comparison of mature amino acid sequences for various interferon (IFN) molecules after removal of the signal peptide

\begin{tabular}{lccc}
\hline & \multicolumn{3}{c}{ Identical residues (\%) } \\
\cline { 2 - 4 } & $\begin{array}{c}\text { Ovine } \\
\text { trophoblast } \\
\text { IFN* }\end{array}$ & $\begin{array}{c}\text { Bovine } \\
\text { IFN- } \alpha_{1} \dagger\end{array}$ & $\begin{array}{c}\text { Bovine } \\
\text { IFN- } \alpha_{n}{ }^{\dagger}\end{array}$ \\
\hline Bovine trophoblast IFN & $79 \cdot 7$ & $50 \cdot 6$ & $70 \cdot 4$ \\
Ovine trophoblast IFN & - & 47.6 & 66.3 \\
Bovine IFN- $\alpha_{1}$ & - & - & $53 \cdot 3$ \\
\hline
\end{tabular}

* Stewart et al. (1989b).

tCapon et al. (1985).

Primer extension analysis was performed to determine the transcription initiation site of the gene using a 54 base oligonucleotide complimentary to bases 88-142 of the coding sequence of ovine tIFN. A major product of 214 bases and a minor product of 211 bases were synthesized, and these defined transcription start sites at adenine residues -73 or -70 from the translation start codon. These putative CAP sites were close to, but distinct from, the CAP site sequence CAGAGA which is conserved in previously reported IFN- $\alpha$ genes. Therefore, it appears that the transcription start site of the IFN- $\alpha$ genes expressed in the trophoblast may differ from those of other IFN- $\alpha$ genes. Comparison with $5^{\prime}$ sequences obtained from bovine tIFN cDNAs does not clarify this question, as the cDNA obtained here was not full length (missing 22 nucleotides from the $5^{\prime}$ end) and those of Imakawa et al. (1989) have a marked and unexplained lack of homology with the bovine tIFN gene in this region.

The 5' region of the gene contains sequences characteristic of other eukaryotic genes, including a sequence at -26 from the transcription start site which is similar to the consensus TATA base sequence, and a possible CAAT box between bases -105 and -99 . Upstream of base -38 the sequence remains similar to bovine IFN $-\alpha_{11}$ but the degree of homology is reduced. The region -106 to -54 corresponds to the region known to be responsible for viral induction in human IFN$\alpha_{1}$ and with a similar region in human IFN- $\beta$. The homology of the virus response element to bovine IFN- $\alpha_{11}$ with the analogous region of bovine tIFN is $74 \%$. The trophoblastic sequence contains the characteristic high frequency of purine residues typical of this region of IFN- $\alpha$. Aligning 
the bovine trophoblast $5^{\prime}$ flanking sequence with the consensus sequence of Ryals et al. (1985; Fig. 3) reveals that the nucleotides of the consensus sequence are mainly represented. Furthermore, alignment with the $5^{\prime}$ sequences given by Dinter \& Hauser (1987) shows that $80 \%$ of residues in the tIFN promoter are represented in at least one of a range of mouse, human or bovine $\alpha$ - or $\beta$-viral response elements. However, the hexamer sequences identified as responsible for viral responsiveness in human IFN (Fujita et al., 1987) are only weakly represented in bovine IFN- $\alpha_{n}$ and tIFN, although the tetramer GAAA appears three times. A sequence similar to that of the negative regulatory domain of the IFN- $\beta$ promoter is not found in bovine tIFN. As a result of these comparisons it is probable that bovine tIFN can be induced by viral infection, but sequence differences do exist and further experiments with a bovine IIFN promoter will be required to confirm this.
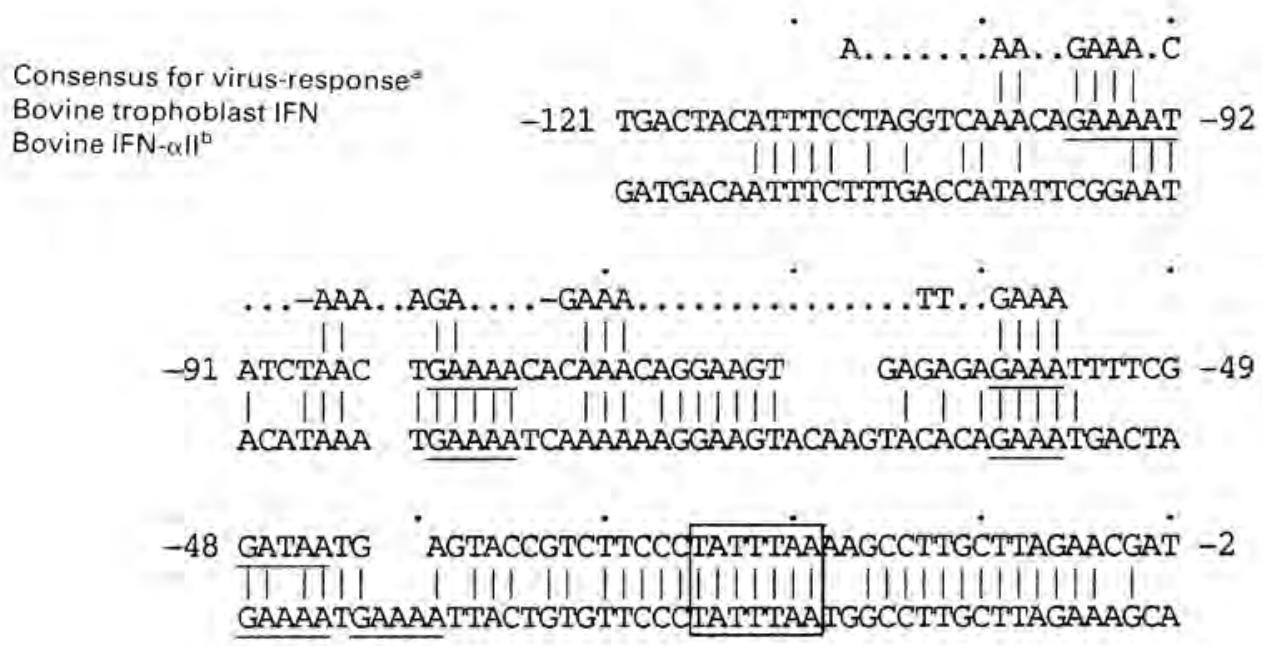

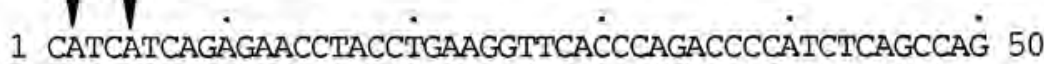

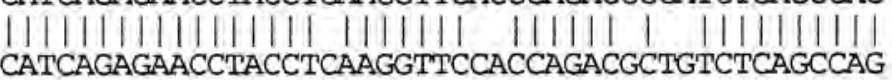
TGGCATCAGAGAACCTACCTCAAGGTTCCACCAGACGCTGTCTCAGCCAG

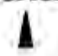

51 CCCAGCAGCÁGCCACATCTTCCC

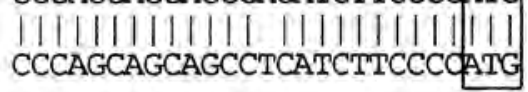

77

Fig. 3. The $5^{\prime}$ flanking sequences of the bovine tIFN gene aligned with the consensus sequence for viral induction of human IFN- $\alpha_{1}$ and IFN- $\alpha_{i}$ derived by Ryals et al. (1985) and with bovine IFN- $\alpha_{11}$ (Capon et al., 1985). Dots represent nucleotides which are not conserved in all IFNs described. Numbering is from the CAP site. The tetramer GAAA has been underlined wherever it occurs in the virus response region. The TATA box and translation initiation site are boxed, and arrows indicate transcription start sites. (From Stewart et al., 1990.)

\section{In-vivo experiments}

\section{Studies with recombinant bovine $\alpha$-interferon}

A high level of embryo mortality is known to occur in domestic ruminants during early pregnancy coincident with the period of maternal recognition of pregnancy. It is possible that a failure of the timing and/or the intensity of the embryonic antiluteolytic signal could be implicated in causing some embryo loss. As described above, the trophoblast proteins responsible for the establishment of pregnancy in sheep and cows are interferons of the $\alpha$ family which interact with sheep 
endometrial receptors to reduce the secretion of the uterine luteolysin PGF- $2 \alpha$ permitting the continued secretion of luteal progesterone. It was therefore of interest to establish whether an available recombinant $\alpha$ interferon produced initially for study of its antiviral activity (brIFN; gift of Ciba Geigy, Basle, Switzerland) extended luteal function in cyclic sheep. Previous investigations (Stewart et al., 1989a) had shown that brIFN exhibited $40 \%$ amino acid sequence homology with tIFN and that unlabelled brIFN could displace the binding of ${ }^{125} \mathrm{I}$-labelled IFN to sheep endometrial receptors. However, the level of binding with the brIFN to receptors was only $20 \%$ that obtained with a ${ }^{125}$ I-labelled human interferon (Sigma, Poole, Dorset, UK).

The results of these initial studies showing that brIFN does extend luteal function in ewes have been reported (Stewart et al., 1989a). This report extends these observations, particularly by comparing the effects of systemic and intrauterine administration of brIFN to sheep and by investigating suppression of secretion and/or release of uterine PGF-2 $\alpha$ measured on Days 14 and 15 after oestrus, the period of expected luteolysis in the normal cyclic ewe.

Two series of experiments have been completed during the breeding season using polled Dorset ewes to study the ability of brIFN to extend cycle length, using the general protocol previously described (Stewart et al., 1989a). Oestrus and ovulation were synchronized in the ewes by using a progestagen-releasing intravaginal sponge (Chronogest, Intervet, Cambridge, UK) for 12 days. After sponge removal, each ewe received 320 i.u. PMSG (Intervet) and $350 \mu \mathrm{g}$ cloprostenol (Estrumate, Coopers Animal Health, Crewe, UK) by intramuscular injection. Oestrus was detected using raddled vasectomized rams. When required, bilateral uterine catheters were inserted on Day 7 after oestrus, using appropriate anaesthetic and sterile surgical procedures as previously described (Stewart et al., 1989a). In all sheep a jugular venous catheter was inserted for routine blood collection procedures. Daily blood plasma samples were assayed to determine progesterone concentrations and therefore cycle length, and all ewes were slaughtered on Day 19 after oestrus when the reproductive tracts were examined for corpora lutea and, when appropriate, to confirm the position and patency of uterine cannulae. Animals were considered to be in the luteal phase if plasma progesterone concentrations were $\geqslant 0+3 \mathrm{ng} / \mathrm{ml}$. For statistical analysis animals with corpora lutea at slaughter on Day 19 were allocated a cycle length of 20 days. Methods for procedures and validation of RIAs for the stable plasma PGF-2 $\alpha$ metabolite 13,14-dihydro-15-keto PGF (PGFM) and for plasma progesterone were as described by Parkinson \& Lamming (1990).

In Exp. 1, three doses $(200 \mu \mathrm{g}, 667 \mu \mathrm{g}$ and $2000 \mu \mathrm{g}$ respectively) of brIFN were administered into the uterus daily by constant infusion from Days 9 to 19 after oestrus. A group of control ewes $(\mathrm{N}=11)$ received the vehicle diluent by the intrauterine route over the same period. An additional group of ewes received $2000 \mu \mathrm{g}$ brlFN by constant intrauterine infusion from Days 12 to 15.

In Exp. 2 intramuscular administration of brlFN was compared with intrauterine infusion, using 5 ewes/group. Negative control ewes received the vehicle diluent (i.m.) from Days 9 to 15 . Positive control ewes received $2000 \mu \mathrm{g}$ brIFN into the uterus between Days 12 and 15. Two additional groups received $2.5 \mathrm{mg}$ brIFN i.m. twice daily from Days 9 to 15 or 12 to 15 after oestrus respectively. In all ewes in both experiments, PGF- $2 \alpha$ secretion was assessed on Days 14 and 15 by measuring PGFM concentrations in samples collected hourly for $8 \mathrm{~h}$.

The results are presented in Figs 4 and 5 which include data on the percentage of ewes with extended oestrous cycles and the treatment effect on cycle length. A dose of $200 \mu \mathrm{g}$ brIFN infused into the uterus was not effective in extending the cycle, but $2000 \mu \mathrm{g}$ brlFN given by the same route between Days 9 and 19 or 12 and 15 was effective in that a significantly higher percentage of ewes had extended cycle lengths. The lower infusion rate of $667 \mu \mathrm{g} /$ day was also effective in significantly extending cycle length, and appears to approximate the daily threshold dose. As shown in Fig. 5 both 667 and $2000 \mu \mathrm{g}$ brIFN infused into the uterus significantly depressed mean PGFM concentrations on Days 14 and 15 when compared to the control group, but sheep receiving the $200 \mu \mathrm{g}$ daily dose surprisingly showed higher $(P<0.05$, Day 14) PGFM values than did controls.

The results for Exp. 2, also shown in Figs 4 and 5 for comparison, confirm that $2000 \mu \mathrm{g}$ brIFN infused into the uterus daily from Days 12 to 15 significantly extends cycle length with a significant 

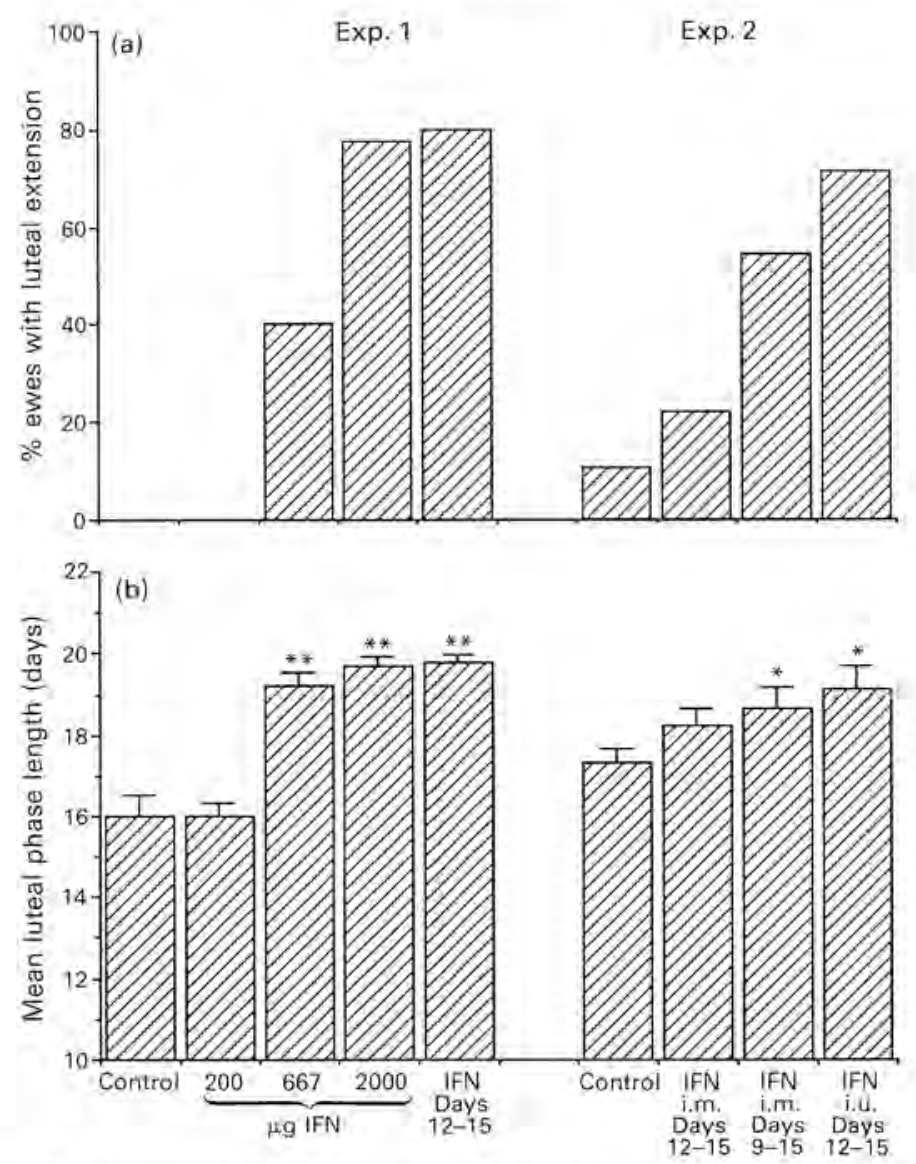

Fig. 4. Effects of intrauterine (i.u.) or systemic (i.m.) administration of bovine $\alpha_{I}$ interferon (brIFN) on (a) \% of ewes with luteal function extended beyond Day 19 and on (b) mean $( \pm$ s.d.) luteal phase length. There were at least 5 ewes/group. In (a) combined increase in ewes with luteal extension $P<0.01$ for Exp. 1 and $P<0.05$ for Exp. 2 (G test); in (b) $* P<0.05$, $* * P<0.01$ (analysis of variance). For treatment see text.

suppression of PGFM concentrations on Day 14-15, and that i.m. administration of $2.5 \mathrm{mg}$ brIFN twice daily from Days 9 to 15 also achieves this effect. However, a similar i.m. regimen from Days 12 to 15 was not effective, the degree of cycle length extension being intermediate between that of control ewes and the Day 9-15 brIFN i.m. treatment.

\section{Effect of brIFN on body temperature}

Intramuscular injection or intrauterine infusion both caused an increase in rectal temperature (Fig, 6). In both cases, this increase occurred only after the initial brIFN treatment; subsequent treatments had no effect on temperature. Intramuscular injection of brIFN caused a $1.25-1 \cdot 5^{\circ} \mathrm{C}$ increase with the peak occurring $3 \mathrm{~h}$ after injection ( $3 \mathrm{~h}$ was the earliest measurement obtained), whereas intrauterine infusion resulted in an increase of $0.75^{\circ} \mathrm{C}$, with the peak occurring at $6 \mathrm{~h}$.

\section{Summary of in-vivo effects}

These studies therefore confirm that the brIFN studied (Ciba Geigy), like conceptus secretory proteins and tIFN, significantly extended interoestrous intervals when infused into the uterus of 


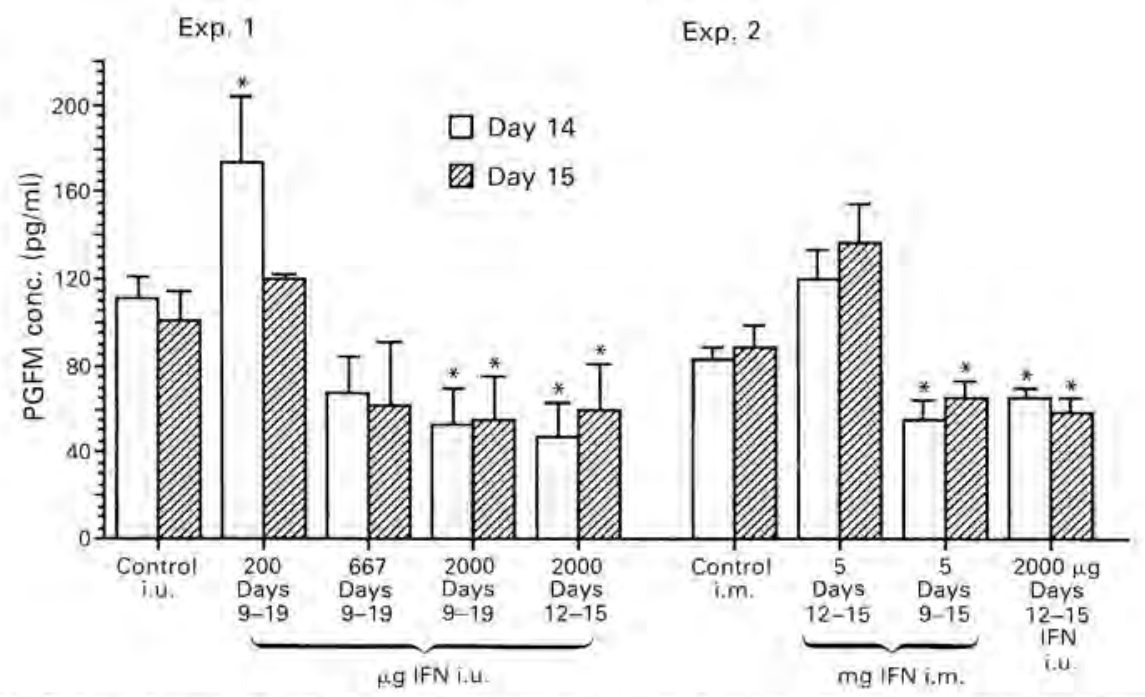

Fig. 5. Effect of intrauterine (i.u.) and systemic (i.m.) administration of bovine $\alpha_{1}$ interferon on mean plasma PGFM of cyclic ewes on Days 14 and 15 . Values are mean \pm s.e.m. for $\geqslant 5$ ewes/ group. ${ }^{*} P<0.05$ compared with control value on that day.
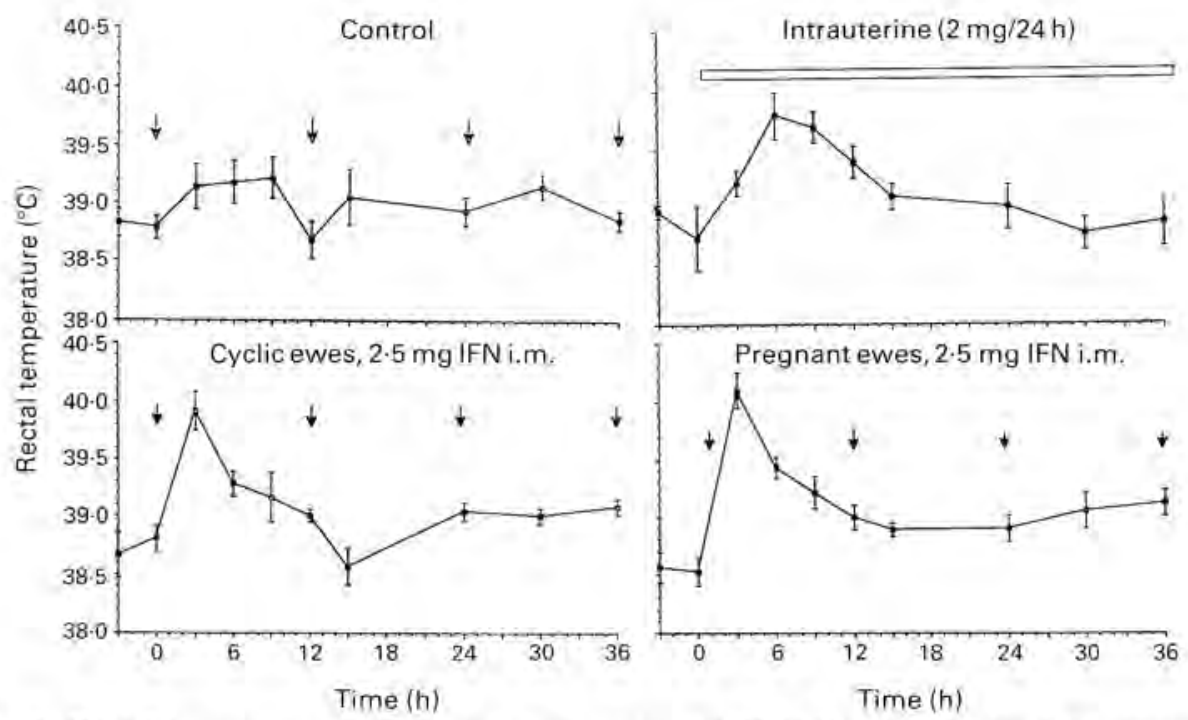

Fig. 6. Rectal temperature changes in ewes receiving brIFN (bar and arrows) by constant intrauterine infusion or by twice daily intramuscular (i.m.) injection compared to vehicleinjected control ewes.

cyclic ewes over the period equivalent to the maternal recognition of pregnancy in sheep (i.e. Days $12-15$ after oestrus). This effect was accompanied by suppression of PGF-2 $\alpha$ secretion as revealed by lower plasma PGFM values on Days 14 and 15 after oestrus. Systemic administration of brIFN was less effective in extending luteal function and suppressing PGF-2 $\alpha$ secretion in cyclic sheep and at the dose used required initiation earlier than with intrauterine infusion, administration between Days 9 and 15 being effective while that between Days 12 and 15 was not. 


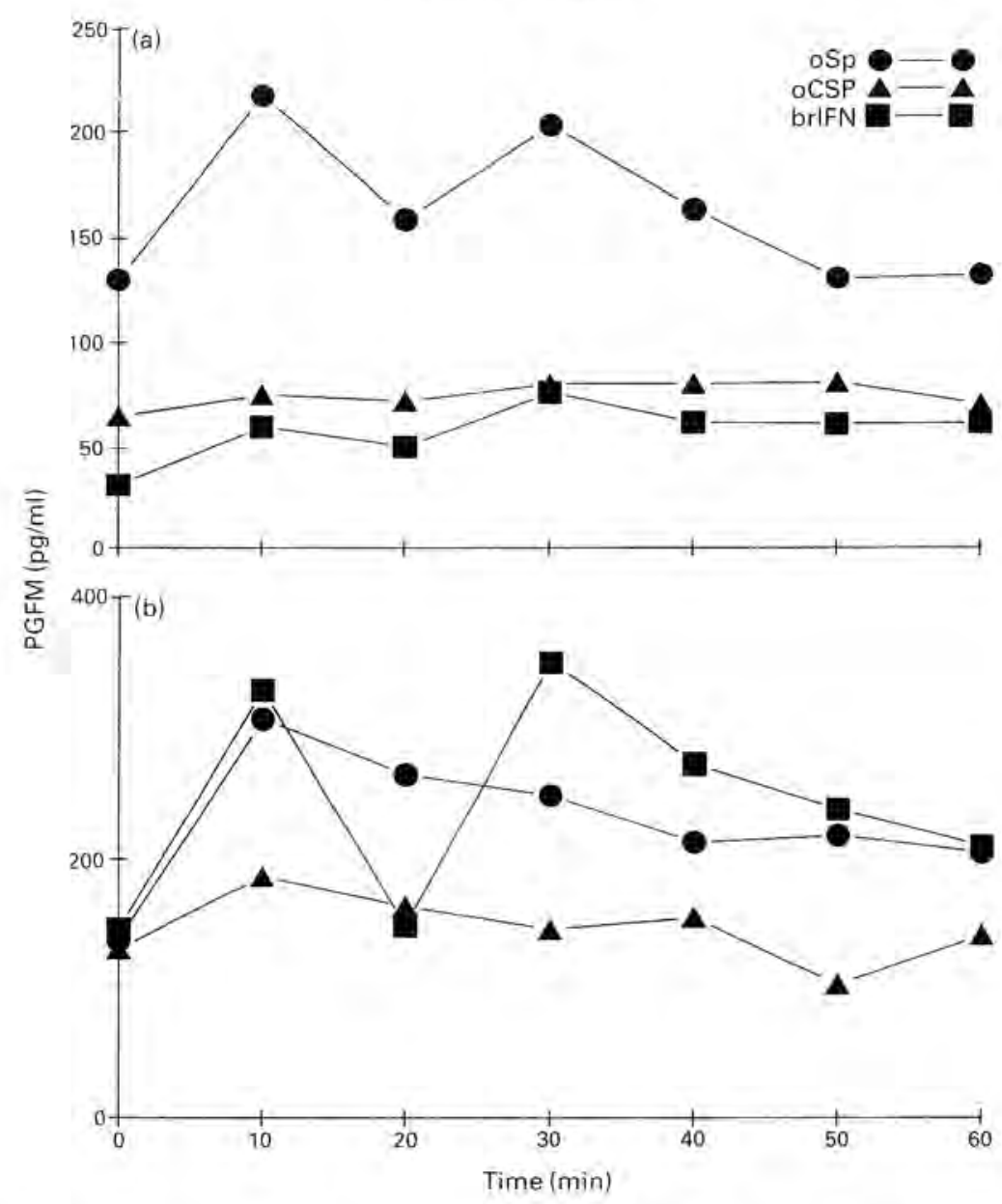

Fig. 7. PGFM concentrations in plasma after oxytocin challenge for (a) cyclic ewes receiving intrauterine infusions of serum proteins (oSP), Day-16 conceptus secretory proteins (oCSP) or bovine recombinant interferon $\alpha_{1}$ (brIFN) and (b) ovariectomized ewes treated with progesterone and intrauterine infusions of OSP, oCSP and brIFN. Mean endometrial oxytocin receptor concentrations were (a) 884,76 and $153 \mathrm{fmol} / \mathrm{mg}$ protein and (b) 690,303 and $857 \mathrm{fmol} / \mathrm{mg}$ protein for the OSP, oCSP and brIFN treated groups, respectively. In (a) the oCSP and brIFN treated ewes were not different from each other as measured by oxytocin receptor concentrations or plasma PGFM concentrations after oxytocin challenge. The oCSP- and brIFNtreated ewes combined had lower oxytocin receptor concentration $(P<0.05)$ and less PGFM in plasma $(P<0.05)$ after oxytocin challenge than did ewes treated with oSP. In (b) the oSP. and brIFN-treated ewes did not differ for oxytocin receptor concentration or PGFM. The oSP and brIFN groups combined had higher $(P<0.05)$ oxytocin receptor concentrations and PGFM $(P<0 \cdot 1)$ values than did oCSP-treated ewes.

\section{The mechanism of the antiluteolytic action of trophoblast and recombinant interferon}

It has been shown that the ovine tIFN was the only protein secreted by the sheep conceptus which could extend the interoestrous interval when infused into the uterus of cyclic ewes (Vallet $e t$ al., 1988). It has also been shown that this extension was due to the inhibition of PGF-2 $\alpha$ release 
caused by oestradiol and oxytocin. It has been suggested that oestradiol-and oxytocin-induced release of PGF-2 $\alpha$ are mediated through the oxytocin receptor in endometrium (McCracken, 1980). Thus a possible mechanism for tIFN-induced interruption of the cycle is via inhibition of endometrial oxytocin receptor concentrations.

To examine this possibility, conceptus proteins collected from cultures of conceptuses recovered on Day 16 of pregnancy (oCSP), brIFN or ovine serum proteins (oSP) were infused ( $1 \mathrm{mg}$ twice daily) into both uterine horns of cyclic ewes on Days 12, 13 and 14 after oestrus. Ewes received oxytocin challenge ( $1 \mu \mathrm{g}$ in $1 \mathrm{ml}$ saline) on Day 15 of the cycle and blood samples were collected just before and at 10-min intervals for $1 \mathrm{~h}$ after oxytocin challenge and measured for PGFM. Ewes were then slaughtered and endometrium was collected and processed for measurement for oxytocin receptor. Both the oCSP and brIFN inhibited $(P<0.05)$ endometrial oxytocin receptor and oxytocin-induced PGF release (Fig. 7a) suggesting that a decrease of endometrial oxytocin receptor concentration is the mechanism whereby both the natural and recombinant IFNs extend the interoestrous interval.

How the natural and recombinant interferons act to inhibit endometrial oxytocin receptor concentrations requires an understanding of the control of these receptors during the cycle. McCracken (1980) proposed that oestradiol at the end of the cycle induces these receptors. Recent evidence, however, suggests that this hypothesis is incorrect. Vallet et al. (1990) have implicated progesterone as the main factor involved in controlling endometrial oxytocin receptor concentrations. Progesterone treatment of suitably pretreated ovariectomized ewes first inhibits then stimulates endometrial oxytocin receptor expression. Since tIFN does not have a direct effect on endometrial response to oxytocin (Vallet \& Bazer, 1989) it is likely that tIFN inhibits expression of endometrial oxytocin receptors by prolonging the inhibitory effect of progesterone.

To test this hypothesis, ewes were ovariectomized and then allowed to recover for 1 week. Ewes then received fluorogestone acetate-containing intravaginal pessaries for 10 days, followed by oestradiol treatment ( $25 \mu \mathrm{g}$ twice daily for 2 days) and subsequently progesterone ( $10 \mathrm{mg}$ twice daily for 12 days), a treatment that increases both endometrial oxytocin receptors and uterine responsiveness to oxytocin (Vallet et al., 1990). Ewes received intrauterine infusions of oCSP, brIFN or oSP ( $1 \mathrm{mg}$ ) into both uterine horns twice daily on Days 10,11 and 12 of progesterone treatment. On the morning of the following day, ewes were challenged with oxytocin and endometrium was collected to measure endometrial oxytocin receptor concentrations as described above. In this experiment, only oCSP inhibited endometrial oxytocin receptor $(P<0.05)$ (Fig. 7b) and had only a marginal $(P<0 \cdot 1)$ inhibitory effect on uterine responsiveness to oxytocin as measured by PGFM. The brIFN had no effect on either oxytocin receptor level or PGFM response to oxytocin.

There are several possible explanations for the difference between the results of this experiment with ovariectomized hormone-treated ewes and the previous experiment with cyclic ewes. First, it is possible that oCSP contain factors, other than IFN, which suppress oxytocin receptor concentrations in ovariectomized ewes. However, the results of Vallet et al. (1988) indicate that tIFN is the only protein in oCSP which extends the cycle. A second possibility is that the timing of infusion in the ovariectomy experiment with respect to the progesterone treatment was not optimal. Vallet et al. (1990) reported that oxytocin receptor concentrations were low after 5 days and higher after 12 days of progesterone treatment. Progesterone therefore induces oxytocin receptor between Days 5 and 12 (now known to be by Day 10: unpublished data). It is possible that receptor concentrations were already increased when infusions began. It is also possible that the optimum effect of oCSP and brIFN requires that they be administered before the increase in receptor concentration occurs; this is what occurs in vivo during pregnancy. This explanation implies that oCSP/tIFN is more potent than brIFN in suppressing oxytocin receptor levels. In fact, antiviral activity of oCSP and brIFN infused into the ovariectomized ewes was 10 times greater than that of brIFN, and this is a possible explanation. Therefore, when timing of infusion was not optimal, only oCSP may have been potent enough to inhibit the expression of the oxytocin receptor. 
Financial support and gifts of material were provided by Ciba-Geigy (brIFN) and Hoechst (oxytocin).

\section{References}

Bazer, F.W., Vallet, J.L., Roberts, R.M., Sharp, D.C. \& Thatcher, W.W. (1986) Role of conceptus secretory products in establishment of pregnancy. $J$. Reprod. Fert. 76, 841-850.

Caldwell, B.Y., Rowson, L.E.A., Moor, R.M. \& Hay, M.F. (1969) The utero-ovarian relationship and its possible role in fertility, I. Reprod. Fert, Suppl. 8. 59-76.

Capon, D.J., Shepard, H.M. \& Goeddel, D.V. (1985) Two distinct families of human and bovine interferon- $\alpha$ genes are co-ordinately expressed and encode functional polypeptides. Molec. cell. Biol. 5, 768-779.

Charlier, M., Hue, D., Martal, J. \& Gaye, P. (1989) Molecular cloning, cDNA structure and expression of ovine trophoblastin: identification as a class II alpha interferon. Gene 77, 341-348.

Charpigny, G., Reinaud, P., Heut, J.-C., Guillomot, M., Charlier, M., Pernollet, J.-C. \& Martal, J. (1988) High homology between a trophoblastic protein (trophoblastin) isolated from ovine embryo and $\alpha$ interferons. FEBS Letts. 228, 12-16.

Denamur, R. \& Mauleon, P. (1963) Endocrine control of persistence of the corpus luteum in sheep. C.r. Hebd. Séanc. Acad. Sci. Paris D 257, 527-530.

Dinter, H. \& Hauser, H. (1987) Co-operative interaction of multiple DNA elements in the human IFN- $\beta$ promoter. Eur. J. Biochem. 166, 103-109.

Farin, C.E., Imakawa, K. \& Roberts, R.M. (1989) In situ localization of $m$ RNA for the interferon, ovine trophoblast protein-1, during early embryonic development of the sheep. Molec, Endocr. 3, 1099-1107.

Flint, A.P.F. \& Hillier, K. (1975) Prostaglandins and reproductive processes in female sheep and goats. In Prostaglandins and Reproduction, pp. 271-308. Ed. S. M. M. Karim. MTP Press Ltd., Lancaster.

Flint, A.P.F., Sheldrick, E.L., McCann, T.J. \& Jones, D.S.C. (1990) Luteal oxytocin: characteristics and control of synchronous episodes of oxytocin and PGF $_{2 x}$. Dom. Anim. Endocr. 7, 3-20.

Fujita, T., Shibuya, H., Hotta, H., Yamanishi, K. \& Taniguchi, T. (1987) IFN- $\beta$ regulation: tandemly repeated sequences or a synthetic $6 \mathrm{bp}$ oligomer function as a non-inducible enhancer. Cell 49, $357-367$

Goding, J.R., Baird, D.T., Cumming, I.A. \& McCracken, J.A. (1972) Functional assessment of autotransplanted endocrine organs. Acta endocr., Copenh., Suppl. 158, 169-191.

Godkin, J.D., Bazer, F.W. \& Roberts, R.M. (1984) Ovine trophoblast protein I, an early secreted blastocyst protein, binds specifically to uterine endometrium and affects protein synthesis. Endocrinology 114, $120-130$.

Hansen, T.R., Kazemi, M., Keisler, D.H., Malathy, P.-V., Imakawa, K. \& Roberts, R.M. (1989) Complex binding of the embryonic interferon, ovine trophoblast protein-I, to endometrial receptors. $J$. Interferon Res. 9, $215-225$.
Imakawa, K., Anthony, R.V., Kazemi, M., Marotti, K.R., Polites, H.G. \& Roberts, R.M. (1987) Interferon-like sequence of ovine trophoblast protein secreted by embryonic trophectoderm. Nature, Lond. 130, $377-379$.

Imakawa, K., Hansen, T.R., Malathy, P.-V., Anthony, R.V., Polites, H.G., Marotti, K.R. \& Roberts, R.M. (1989) Molecular cloning and characterization of cDNAs corresponding to bTP-1; a comparison with oTP-I and bovine IFN-a $a_{n}$. Molec. Endocr. 3, 127-139.

Martal, J., Lacroix, M-C., Loudes, C., Saunier, M. \& Wintenberger-Torres, S. (1979) Trophoblaslin. an antiluteolytic protein present in early pregnancy in sheep. J. Reprod. Ferı. 56, 63-73.

McCracken, J. (1980) Hormone receptor control of prostaglandin F-2a secretion by the ovine uterus. Adv. Prost. Thromb. Res. 8, 1329-1344.

Moor, R.M. \& Rowson, L.E.A. (1964) Influence of the embryo and uterus on luteal function in the sheep. Nature, Lond. 201, 522-523.

Parkinson, T.J. \& Lamming, G.E. (1990) Interrelationships between progesterone, 13,14-dihydro-15-keto PGF-2 $\alpha$ (PGFM) and LH in cyclic and early pregnant cows. J. Reprod. Fert. 90, 221-233.

Plante, C., Hansen, P.J. \& Thatcher, W.W. (1988) Prolongation of luteal lifespan in cows by intrauterine infusion of recombinant bovine alpha-interferon. Endocrinology 122, 2342-2344.

Pontzer, C.H., Torres, B.A., Vallet, J.L., Bazer, F.W. \& Johnson, H.M. (1988) Antiviral activities of the pregnancy recognition hormone ovine trophoblast protein-I. Biochem. Biophys. Res. Commun. 152, 801-807.

Roberts, R.M., Imakawa, K., Niwando, Y., Kazemi, M., Malathy, P.-V., Hansen, T.R., Glass, A.A. \& Kronenberg, L.H. (1989) Interferon production by the preimplantation sheep embryo. J. Interferon Res. 9, 175-187.

Rowson, L.E.A. \& Moor, R.M. (1967) The influence of embryonic tissue homogenate infused into the uterus. on the life-span of the corpus luteum in the sheep. $J$. Reprod. Fert. 13, 511-516.

Ryals, J., Dierks, P., Ragg, H. \& Weissmann, C. (1985) A 46-nucleotide promoter segment from an IFN- $a$ gene renders an unrelated promoter inducible by virus. Cell 41, 497-507.

Short, R.V. (1969) Implantation and the maternal recognition of pregnancy. In Foetal Autonomy, pp. 2 26. Eds G. Wolstenholme \& M. O'Connor. Ciba Foundation/Churchill, London.

Stewart, H.J. (1990) Trophoblastic factors and the maternal recognition of pregnancy in sheep and cattle. $J$. dev. Physiol. (in press).

Stewart, H.J., McCann, S.H.E., Barker, P.J., Lee, K.E., Lamming, G.E. \& Flint, A.P.F. (1987) Interferon sequence homology and receptor binding activity of ovine trophoblast antiluteolytic protein. $J$. Endocr. 115, R13-R15. 
Stewart, H.J., Flint, A.P.F., Lamming, G.E., McCann, S.H.E. \& Parkinson, T.J. (1989a) Antiluteolytic effects of blastocyst-secreted interferon investigated in vitro and in vivo in the sheep. J. Reprod. Fert., Suppl. 37, 127-138.

Stewart, H.J., McCann, S.H.E., Northrop, A.J., Lamming, G.E. \& Flint, A.P.F. (1989b) Sheep antiluteolytic interferon: $c D N A$ sequence and analysis of mRNA levels. J. molec. Endocr. 2, 65-70.

Stewart, H.J., McCann, S.H.E. \& Flint, A.P.F. (1990) Structure of an interferon- $\alpha_{11}$ gene expressed in the bovine conceptus early in gestation. $J$. molec. Endoci. 4, 275-282.

Vallet, J.L. \& Bazer, F.W. (1989) Effect of ovine trophoblast protein-1, oestrogen and progesterone on oxytocin-induced phosphatidylinositol turnover in endometrium of sheep. J. Reprod. Ferl. 87, $755-761$.

Vallet, J.L., Bazer, F.W., Fliss, M.F.V. \& Thatcher, W.W. (1988) Effect of ovine conceptus secretory proteins and purified ovine trophoblast protein-I on interoestrous interval and plasma concentrations of prostaglandins F-2 $\alpha$ and $\mathrm{E}$ and of 13,14-dihydro-15keto prostaglandin F-2 $\alpha$ in cyclic ewes. $J$. Reprod. Fert 84, 493-504.

Vallet, J.L., Lamming, G.E. \& Batten, M. (1990) Control of endometrial oxytocin receptor and uterine response to oxytocin by progesterone and oestradiol in the ewe. J. Reprod. Fert. 90, 625-634.

Wiltbank, J.N. \& Casida, L.E. (1956) Alteration of ovarian activity by hysterectomy. J. Anim. Sci. 15, 134-140. 
